\title{
SWITCH TO SAVE? COMPARING MUNICIPAL SOLID WASTE EXPENDITURES BASED ON WASTE MANAGEMENT PROVIDER OWNERSHIP
}

\section{Michal Struk *}

Department of Regional Economics and Administration, Faculty of Economics and Administration, Masaryk University - Lipová 41a, Brno, 602 00, Czech Republic

Article Info:

Received:

29 January 2018

Revised:

19 June 2018

Accepted:

3 August 2018

Available online

9 August 2018

Keywords:

Waste management

Municipal expenditures

Public service provision

\begin{abstract}
The debate about public vs. private provision of municipal solid waste management has been going on for several decades with no conclusive evidence in favor of either. The presence of relevant competition in the market seems to be more important than the type of the provider. In this study, we expand on this topic and use empirical evidence to show that what matters most is the willingness of the municipality to switch waste management providers. We compare the municipal solid waste expenditures of more than 60 municipalities in the Czech Republic that changed their waste management provider in 2008-2014, both before and after the change. The results show that such a change can, on average, reduce the expenditure by several percent, and change should therefore be preferred by the municipalities instead of perpetually extending contracts with the current provider. In addition, we show that it does not matter much whether the new waste management provider is a public or private company, as costs are reduced when switching either way.
\end{abstract}

\section{INTRODUCTION}

The issue of public vs. private provision of public services has a long history in the scientific literature. Public services usually originate in connection with two factors: the general public interest in provision of such services and the failure of the private sector in providing such services, typically due to the very high initial costs and the issue of securing sufficient revenue.

Waste management (WM) is one such service. While there is a general consensus regarding the public interest in this service, from the perspective of a private provider there is also the issue of how to persuade people to properly finance it. The common solution is that the municipality, as a public entity, is empowered with enough rights to make people pay for such a service, and then uses the collected revenues to finance it. It is then up to the municipality to delegate the service provision (Kinnaman and Fullerton, 1999), either using its own capacities or contracting out the service.

While the issue of how to raise funds for running the municipal solid waste management (MSWM) might be a simple administrative task (taxes or fees), the question of how to use these funds to secure appropriate services is much more complex.

It is important to remember the difference between the private sector and the public sector. In the private sector, the obvious goal is to make a profit, and the ability to make a profit generally results in the survival of the better service providers over those that are not able to keep up and are subsequently squeezed out by the competition. The trend towards increasing efficiency in service provision is thus secured. However, in the public sector (where waste management falls) the primary goal is the welfare of the people and not profit, although generating at least some profit is still welcome. Thus any measures that would result in improving the provided service, decreasing the related costs, and ideally the combination of both is desirable. Any evidence providing suggestions for selecting a WM provider for the municipality can therefore be useful.

One simple way to divide WM providers in municipalities is into public (contracting in) or private (contracting out) companies. The literature on the subject of public vs. private provision of WM has been examining the issue of company ownership since the 1980s when Domberger et al. (1986) examined municipalities in England but did not find any notable differences between contracting in and contracting out WM service. The only relevant factor in terms of costs was, according to the study, the existence of competitive contracting.

Since then, many studies have examined whether there 
is any significant difference between public and private provision of WM, occasionally slightly favoring one type or the other. Bel and Warner (2008) published a review in which they examined studies dealing with the effect of privatization on cost reduction in WM. Generally, they found little support for a link between privatization and cost savings, as the observed savings are not systematic. The issue identified in the review is that in the research there is rather too much emphasis on the ownership instead of on other aspects that are more important in quasi-markets such as WM with limited numbers of alternative suppliers. Cost savings are simply not systematically found when looking at the issue in terms of the WM provider organizational type. Bel and Mur (2009), Bae (2010), and Jacobsen et al. (2013) provide comparable conclusions that there is no clear evidence in favor of either one in terms of costs and the results are typically mixed (Bel et al. 2010, Simões et al. 2012).

On the other hand, the presence of competition has been identified as important (Szymanski, 1996, Gomez-Lobo and Szymanski, 2001, Bel and Warner, 2008, Jacobsen et al. 2013). Once public providers are forced to compete with private companies, they are likely to achieve comparable results (Kinnaman and Fullerton, 1999).

Bel and Warner (2008) therefore stress that instead of emphasizing the public versus private debate, primary attention should be given to the market structure and whether there is sufficient competition. In the absence of competition, savings are less likely to occur, regardless of the WM provider ownership.

Waste management in Czech municipalities is strongly affected by their size structure. It is not uncommon for a municipality to have a population of less than 1000 , or even less than 500 . Such small municipalities have to rely on contracting out their WM, as it does not make economic sense to have an in-house WM company. But even though the waste sector is becoming more economically attractive, many of these municipalities struggle with increasing costs, as they often have historically relied on only one provider and are reluctant to change. In many cases, they simply perpetually extend the contract with their provider, accepting regular cost increases. Due to the limited administrative capacities in the smallest municipalities, this is often the most convenient solution, although likely also the most expensive.

The efficiency of WM as a public service was examined in more detail in the Czech conditions by Ochrana et al. (2007), who focused on the role of the WM company organizational form in the overall efficiency of the service. The study analyzed the preferred form of service provision, the important criteria when selecting a WM provider, and the reasons leading to municipalities changing WM providers. The authors collected more than 900 survey replies from Czech municipalities and analyzed the answers together with the available data about related municipal expenditure. The outcome of the study is that in-house production of services appears to be the most efficient, but this is because certain related costs of service production are often not directly assigned to the production of these services by the municipalities, and therefore the reported expenditures are lower. Using only expenditures directly reported by the municipalities on these services thus yields inaccurate results, when comparing with the external provision of these services. The least efficient, on the other hand, are municipal companies that were arbitrarily selected without any competition. The overall conclusion of the study is that as long as there is competition, the form of service provider ownership actually might not matter at all.

In order to extend the current research in this area, the research question of our study concerned how switching WM providers affects municipal solid waste expenditure (MSWE) and whether the change in WM provider ownership has any role. Unlike other studies, which usually compare the differences between public and private providers in a selected time period, we use empirical evidence to examine the difference in costs before and after changing WM providers.

\section{MATERIALS AND METHODS}

\subsection{Data}

In this part, we describe the data used in this study and how we obtained them.

There were two primary data sources. Financial data were acquired from a web portal run by the Czech Ministry of Finance called MONITOR. This portal provides information about the budgets of all municipalities in the Czech Republic and presents complex aggregated data about the financial situation of individual Czech municipalities, freely available to the public. Complete detailed data for individual fiscal years can be downloaded for further analysis.

We were specifically interested in the current expenditures of municipalities on MSWM that represent the day-today expenditures of municipalities on MSWM provision. We do not use capital expenditures, as they include primarily occasional investment costs that happen usually only once in a few years, making it problematic to compare among the municipalities, especially those of varying sizes. On the other hand, current expenditures calculated per capita (using municipality population data available through the Czech Statistics Office) generally provide a good basis for comparing expenditures among the municipalities, as they cover approximately the same things in both smaller and larger municipalities.

However, it should be noted that the financial data provided by MONITOR are not always $100 \%$ correct. We collected municipal financial data for several consecutive years, making it possible to see developments over time and to check whether there are any issues with the data, suggested for instance by very high variances between individual years. Such issues are usually the result of a municipality reporting its financial data incorrectly. Typical examples include reporting both current and capital expenditures as current, or failing to differentiate between expenditures from certain subgroups and reporting only aggregated expenditures under the most common category for such groups.

The reasons for such mistakes are mostly municipal staff with insufficient knowledge of how to report municipal expenditures or insufficient time for detailed expen- 
diture reporting. As the majority of municipalities in the Czech Republic are very small with populations of only a few hundred, often there is simply an insufficient administrative capacity for certain tasks.

The second data source was interviews with the local authorities from a sample of municipalities. As we are examining the effect of changing/switching WM providers, we focus only on municipalities where such a change occured. Unlike with the financial data, there is no centralized source where municipalities report how they secure their WM. We contacted over 500 municipalities in the Czech Republic, of which 70 reported a change of WM provider in the last several years. However, due to very large interannual differences caused by combining the expenditures related to building a civic amenity site with the current expenditures, we dropped four municipalities, resulting in a final sample of 66 municipalities.

Most of these municipalities use an external WM company. This makes sense, as due to their relatively small sizes, it is not economical to have their own municipal waste company. Therefore they contract a private, public, or mixed WM company. We now define "municipal", "public", and "mixed" WM ownership types as they are used throughout this study; "private" ownership is self-explanatory.

A "municipal" WM company is usually historically created by a larger municipality for which it provides MSWM; sometimes, it also provides this service for a few neighbouring municipalities. According to the interviews, such a company is usually less focused on profit and is often part of a larger municipal company generally dealing with various technical municipal services. Providing MSWM for additional municipalities serves as a way to better utilize the available infrastructure with a greater focus on profit.

In this study, a "public" WM company is one that is owned by an association of municipalities in which individual municipalities act as the shareholders based on their size and respective financial investments. Each municipality pays this company for the MSWM provision, and it also participates in the profits of the company. However, during our interviews we noted occasional disillusionment with involvement with such companies, as small municipalities have very little say compared to the few larger municipalities.

A "mixed" WM company is usually the result of the previous decision of a larger municipality to partially outsource WM provision, maintaining some participation in the decision making and profit while having an economically strong partner. In such cases, the private part of the mix is often represented by a newly created company owned by an already established player in the waste market. If relevant, this company also provides MSWM for surrounding smaller municipalities, just as with a municipal company.

Based on telephone interviews with responsible local authorities, or alternatively with local authorities with sufficient knowledge of the topic, we matched each municipality with a WM company, a time horizon when this company provided MSWM in the given municipality, and the ownership type of the company.

We then created a dataset for several consecutive years with information about municipalities and their WM companies, ownership type of the WM companies, related municipal expenditures, and any change in the position of the WM company that occurred in the examined time period.

The following three tables include some basic characteristics of the sample used in this study.

\subsection{Methods}

In order to be able to analyze the effect of switching WM companies, we had to adjust the data, as these were collected for a broader time horizon and thus difficult to compare directly. We adjusted the dataset in order to have data in a format reflecting municipal expenditures in the

TABLE 1: Description of the sample (with respect to the year of the provider change).

\begin{tabular}{llllll} 
66 municipalities & Bottom value & Median & Top value & Average \\
\hline Population & 76 & 930 & 9555 & 1391 \\
MSWE per capita & 291 CZK & 518 CZK & 926 CZK & 539 CZK \\
\hline
\end{tabular}

Source: Czech Statistical Office, Czech Ministry of Finance

TABLE 2: Year of the waste management company change, 66 municipalities.

\begin{tabular}{c|cccccccc} 
Year & $\mathbf{2 0 0 8}$ & $\mathbf{2 0 0 9}$ & $\mathbf{2 0 1 0}$ & $\mathbf{2 0 1 1}$ & $\mathbf{2 0 1 2}$ & $\mathbf{2 0 1 3}$ \\
\hline No. of changes & 2 & 8 & 5 & 6 & 14 & 19 \\
\hline \% of the sample & 3 & 12 & 8 & 9 & 12 & 21 & 29 \\
\hline
\end{tabular}

Source: own data

TABLE 3: Waste management company ownership before/after the change, 66 municipalities.

\begin{tabular}{l|c|ccc} 
Ownership & Private & Public & Municipal \\
\hline Before the change & 50 & 8 & 6 \\
\hline$\%$ of the sample & 76 & 31 & 12 & 9 \\
\hline After the change & 47 & 29 & 4 \\
\hline$\%$ of the sample & & 44 & 2 \\
\hline
\end{tabular}

Source: own data 
year before changing WM provider (year -1), in the year when the WM provider was changed (year 0 ), in the subsequent year (year +1 ), etc. After this adjustment, we aligned the individual municipal data in order to have matching periods. Doing this means we do not need to consider in which absolute year the WM provider changed, as we have a relative timeline, which is more useful for our purposes. Instead of 66 changes occurring over a seven-year horizon, we now have a dataset with the WM provider change occurring in the same relative period.

With the municipal data about the WM provider change aligned to the same relative (year 0 ) period, we calculated the relative differences in municipal expenditure per capita from the period before the change of the WM provider in terms of year +1 and year +2 .

Calculating these differences allows us to directly see how MSWE changed once the municipality switched to a different WM provider.

In addition, our sample of municipalities was divided into groups based on the change of the WM provider ownership type. We differentiate four types of WM provider ownership. After the data collection, we concluded that there are five common situations with WM provider changes in terms of ownership; these are discussed later in the study. After making this distinction, each situation can be analyzed separately and compared.

\section{RESULTS AND DISCUSSION}

Figure 1 shows the differences in aggregated data from municipalities in the years before and after the municipality changed its WM provider. Provided data are calculated as the MSWE per capita.

The data show that once the WM provider change occurred, the average per capita expenditure decreased in the following year on average by $6 \%$ (the median decrease was $4 \%$ ). While this might not seem that significant, even such a small change can make a difference in terms of municipal finance where budgets are often very limited. If we consider such a savings for a period of several years, a munici- pality can save enough to make a larger investment that could further improve its WM or can alternatively tackle some other important issue in the municipality. Moreover, in municipalities that perpetually extend their contract with the WM company, it is common that MSWE increases each year by a few percent. Reductions in MSWE instead of standard annual increases thus represent even greater savings

Figure 2 shows the relative interannual changes in MSWE of individual municipalities. In this figure, we see that switching WM providers does not always lead to decreased MSWE. There may be several reasons for this. First, the new WM provider might provide a broader range of waste services, which logically results in higher costs. For instance, the collection frequency might be increased, additional waste fractions might be separately collected, etc.

Second, although being more expensive than before, the new provider might still be cheaper compared to the situation with the previous WM company. Jump increases in costs requested by the original WM providers were mentioned by several local authorities as the decisive factor in switching to a different WM provider.

Third, there might be some additional costs included in the reported MSWE by the municipality that coincidentally occurred in the same year as the WM provider change. For instance, many municipalities begun to separately collect biowaste during this period, which required purchasing composters or additional bins for biodegradable waste. Even though such purchases occur irregularly, technically they can count as current expenditure, leading to the increased reported MSWE in a given year and might result in overall increase of MSWE by several per cent.

Nevertheless, Figure 2 shows that the majority of municipalities experienced a decrease in MSWE after they switched their WM provider. Almost 30\% report a decrease in MSWE by up to $10 \%$, while an additional almost $30 \%$ report even higher MSWE reduction, with a few municipalities saving more than $40 \%$. Few municipalities reported an increase in MSWE by over $30 \%$, but based on our experience such an increase is very probable due to the reasons men-

$\square$ Average MSWE per capita

口Median MSWE per capita

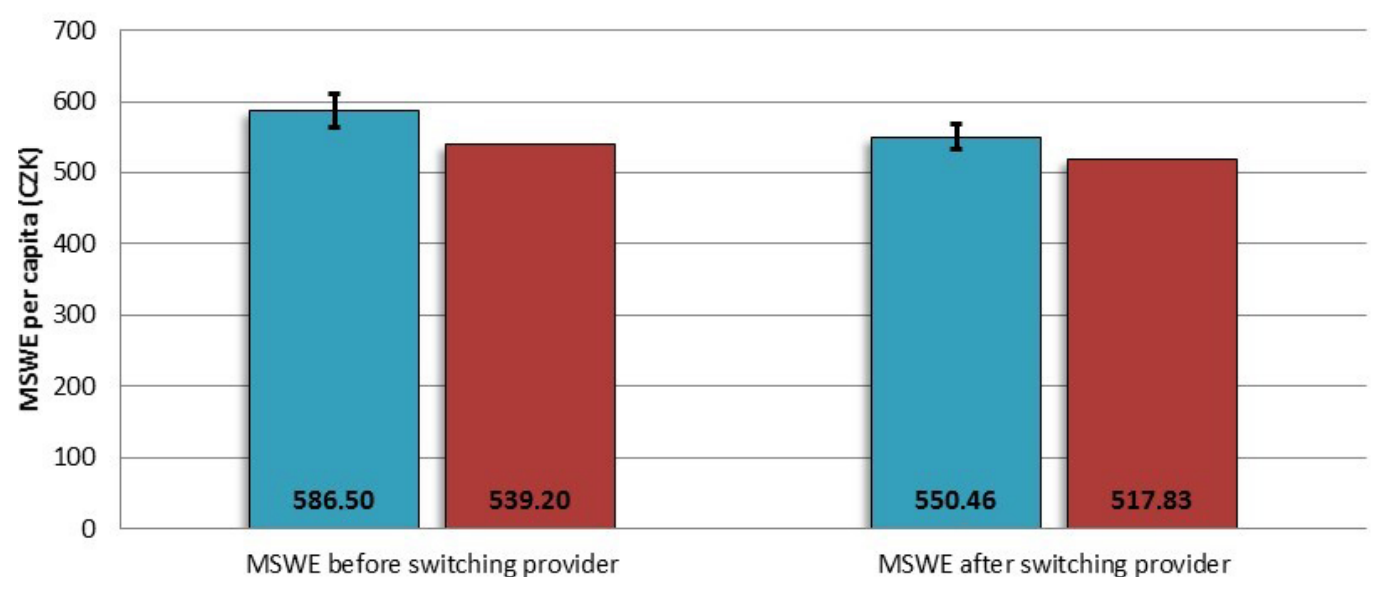

FIGURE 1: Interannual changes in MSWE after switching waste management provider (66 municipalities), standard errors for averages included - Source: own construction 


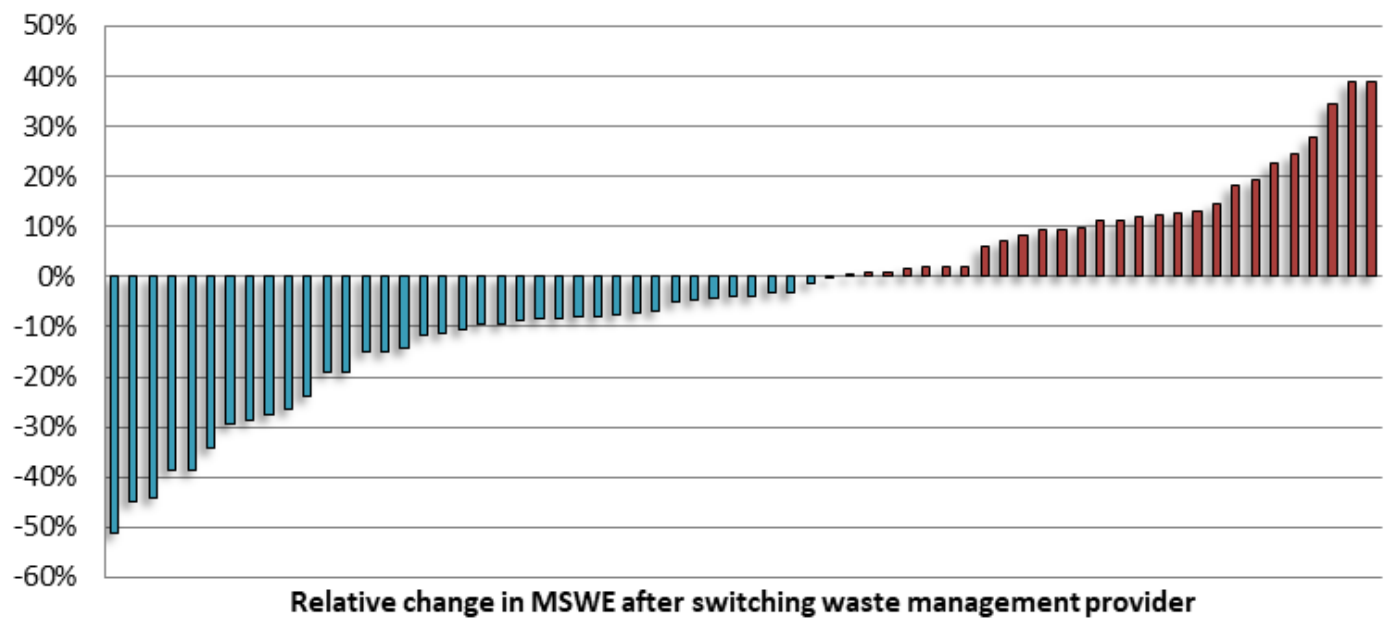

FIGURE 2: Relative changes in MSWE of individual municipalities after switching waste management providers (66 municipalities) - Source: own construction

tioned above. Overall, half of the municipalities from the sample did not experience a difference of more than $\pm 10 \%$ in their MSWE.

Szymanski and Wilkins (1993) and Gomez-Lobo and Szymanski (2001) mention that while there might be great cost savings in the initial year, this advantage tends to diminish quickly in the following years, resulting again in higher costs and probably in another public tender. In part of our sample, we were able to obtain MSWE data from the second year after the change in WM provider; this is presented in Figure 3.

Figure 3 shows that after two years, the savings still exist (on average $3.5 \%$ lower MSWE than in the period before the change of the WM provider), but are beginning to diminish, which is in accordance with the mentioned literature. Competitive tendering every few years might have the potential to keep the MSWM costs down. On the other hand, each individual municipality has to decide how often it should opt for the next tendering, as such action brings additional costs to the municipality.

Jacobsen et al. (2013) suggest a biannual tendering system in order to find the provider with the best offer. One municipality in our sample utilized biannual tendering through electronic bidding applications and was able to get a much better contract than before, although this was largely due to the rather poor starting condition of WM in this particular municipality.

The Czech Republic has a very fragmented municipal structure and, in many cases, the fixed costs associated with WM provider tendering might represent a significant part of the total annual MSWE and might even exceed the potential savings. In such cases, it is actually more economical to stay with the current, albeit probably more expensive, WM provider than to look for a possibly cheaper one, and thus the WM provider change is likely to occur less frequently. The general suggestion here would still be to actively pursue public tendering, although somewhat less frequently.

A different perspective on this issue comes from the WM providers themselves. From their position, frequent changes are typically far from desirable. An ideal situation for a WM provider would probably be to have a secured

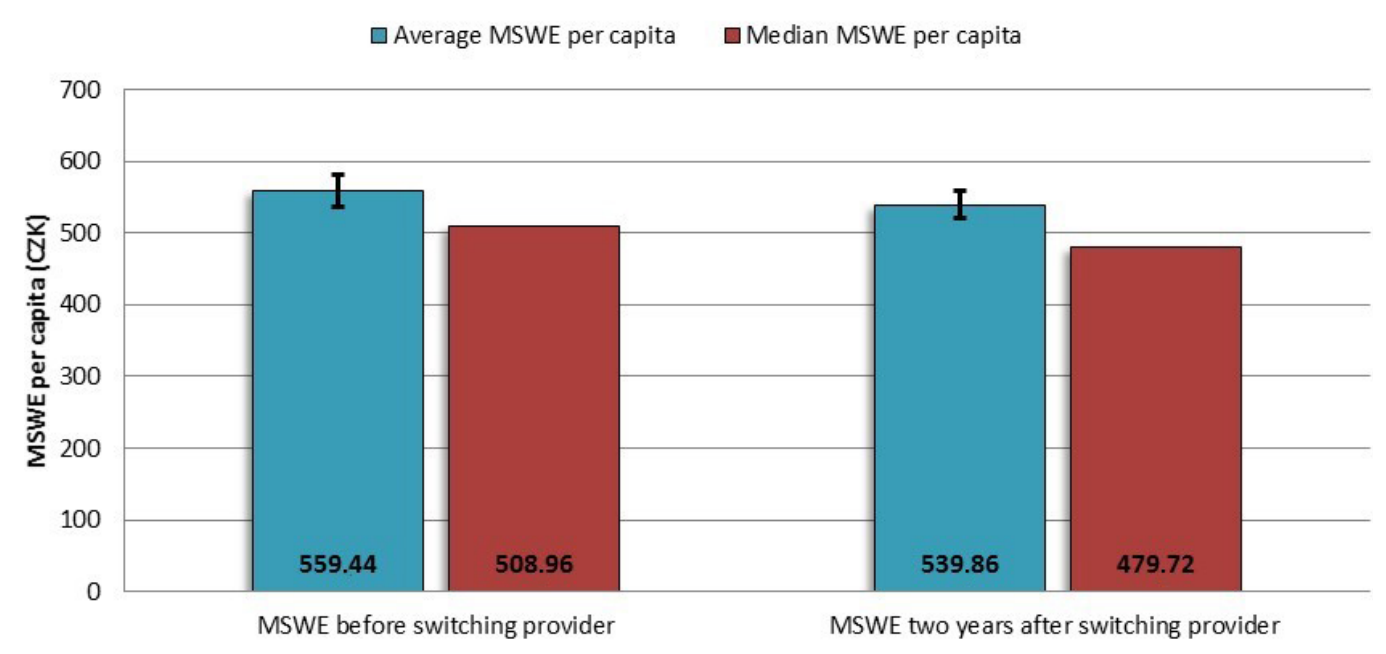

FIGURE 3: Comparison of MSWE before and two years after switching waste management provider (52 municipalities), standard errors for averages included - Source: own construction 
contract for an infinite period with gradual increases in prices over the time. In such a situation, they could plan far into the future and not need to worry about the competition. This is the classical market situation, in which the interests of the customer (municipality) compete with the interests of the supplier (WM provider). The customer wants as much as possible while paying as little as possible, while the supplier wants the opposite. If these two sides are able to find an intersection, a deal occurs. From the perspective of the municipality as the customer, it is important to have a sufficient choice of WM providers, so that the municipality does not have to compromise that much in terms of the quality of the contracted service and the associated price. But of course, if the available offer is not good enough, the municipality always has the option of providing WM services itself, and sometimes this actually can be the best available option.

Figure 4 shows the changes in MSWE differentiated by the type of the WM provider ownership before and after the municipality changed WM providers. We can see that savings are possible in any kind of scenario, independent of the original type of WM provider ownership.

Slight savings are reported whether a municipality switches from a private WM provider to a public one (in our conditions, owned by an association of municipalities) or vice versa. Larger savings seem to be possible when switching between private waste companies and municipal waste companies, but again, the data suggest that this goes both ways. We therefore cannot draw a clear conclusion in terms of savings of whether it is better to choose a private or public waste company. The observation that there is rather little difference in waste-related costs between public and private providers is in accordance with many other authors (Domberger et al., 1986, Szymanski, 1996, Bel and Fageda, 2010), as well as with the observation that the existence of competition is much more important than the type of provider (Gomez-Lobo and Szymanski, 2001, Dijkgraaf and Gradus, 2007, Bel and Warner, 2008).

However, the highest amount of cases where MSWE increased were in individual municipalities changing from a private to a public company. This somehow contradicts Bel and Costas (2006), who suggest that intermunicipal cooperation (which is, in our case, represented by a waste company owned by an association of municipalities) might be a good alternative for small municipalities with limited potential external WM providers.

The observed MSWE increase in multiple cases when switching to a public provider might partially explain the disillusionment that some local authorities expressed in interviews after becoming a member of an association of municipalities in order to utilize the MSWM services of the related public waste company. Accordingly, it might be wise for a municipality considering a switch to a public WM company to examine whether the potential savings are truly there in comparison with the other options.

According to Massarutto (2007), even better results can be achieved when competitive tendering is used for separating more specific activities along the value chain. However, based on our experience with local authorities, such separate competions for specific activities in MSWM are very scarce. In our opinion, the problem might also be the small average municipality size in the Czech Republic: it does not make much economic sense for the waste companies to compete for only specific activities in such small municipalities, and thus the separation of MSWM into distinct activities becomes relevant only in larger municipalities. But the results in those few municipalities where separate tenders happen so far seem promising. In combination with the stronger preference for short-term contracts suggested by Simões et al. (2012) this might become a good strategy for municipalities to cut down MSWE and keep them low.

\section{CONCLUSIONS}

As in several previous studies, we examined the differences between public and private provision of municipal solid waste management. However, in contrast to previous studies, we did not focus on the cost difference between various types of waste management provider ownership in a single selected time period, but instead on the changes of waste management costs over time, once the municipality switched to a different waste management provider. This approach does not provide a static perspective on the

$\square$ Relative annual change in MSW expenditure according to the WM provider ownership change

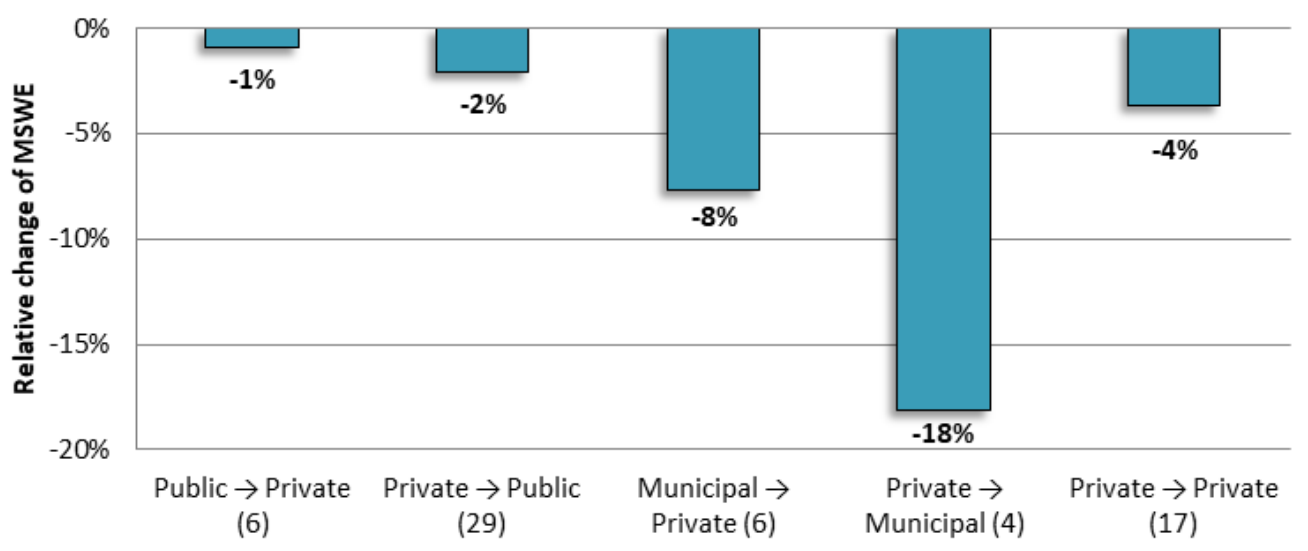

FIGURE 4: Relative changes in MSWE after switching WM provider (62 municipalities) - Source: own construction 
matter, but in our opinion it actually provides a more important dynamic perspective using relative changes, as it overcomes the issue of various initial starting points of the municipalities before switching their providers.

Our results show that a municipality is likely to benefit from changing its waste management provider. The majority of the municipalities in our sample experienced a decrease in their waste management expenditure once they switched providers, on average by $6 \%$ in the first year after the change and in some cases by more than 20 to $30 \%$. The comparatively lower waste expenditure level achieved under the new provider seems to hold even for the following year, although savings tend to slowly diminish, as has been suggested by other authors dealing with this issue. Based on these observations, municipalities should consider actively pursuing regular competitive tendering every couple of years depending on the actual service and the market availability. An active approach in this field seems to pay off relatively well considering the nature of municipal finances.

On the other hand, waste management costs increased in some municipalities, but our evidence indicates that this was caused typically by other factors, such as the extension of activities included in the service provided by the new company. In addition, even though in some cases the waste management costs increased with the new provider, this increase was actually likely lower than the costs would have been with the previous waste management provider, so this can still be considered as an improvement or as an actual savings.

Finally, we examined the differences in waste management expenditures when switching from public to private waste management provider and vice versa. We did not find any significant patterns. It seems that, in accordance with other authors, it actually does not matter much whether the waste provider is public or private, but whether the municipality is willing to regularly engage in competitive tendering for such services. By doing this, the municipality seems to be most likely to get the best available services at reasonable costs. The ownership of the potential service provider does not seem to play an important role, as long as these providers have competition. Sufficient competition ensures that the efficient providers will survive and be able to offer their services to the municipalities. Municipalities therefore should not be biased towards any potential service provider based on its ownership and should approach the question of what provider to choose in a pragmatic way. In this way, municipalities should be able to secure the best combination of quality, scope, and price of the provided services.

\section{ACKNOWLEDGEMENTS}

This article is an outcome of research project TL01000305 by the Technology Agency of the Czech Republic.

\section{REFERENCES}

Bae, S. (2010). Public versus private delivery of municipal solid waste services: The case of North Carolina. Contemp econ policy, 28(3), 414-428.

Bel, G. and Costas, A. (2006). Do public sector reforms get rusty? Local privatization in Spain. J policy reform, 9(1), 1-24.

Bel, G. and Fageda, X. (2010). Empirical analysis of solid management waste costs: Some evidence from Galicia, Spain. Resour conserv recy, 54(3), 187-193.

Bel, G., Fageda, X. and Warner, M. E. (2010). Is private production of public services cheaper than public production? A meta-regression analysis of solid waste and water services. J policy anal manag, 29(3), 553-577.

Bel, G. and Mur, M. (2009). Intermunicipal cooperation, privatization and waste management costs: Evidence from rural municipalities. Waste manage, 29(10), 2772-2778.

Bel, G. and Warner, M. (2008). Does privatization of solid waste and water services reduce costs? A review of empirical studies. Resour conserv recy, 52(12), 1337-1348.

Dijkgraaf, E. and Gradus, R. (2007). Collusion in the Dutch waste collection market. Local gov stud, 33(4), 573-588.

Domberger, S., Meadowcroft, S. A., and Thompson, D. J. (1986). Competitive tendering and efficiency: the case of refuse collection. Fisc stud, 7(4), 69-87.

Gomez-Lobo, A. and Szymanski, S. (2001). A law of large numbers: bidding and compulsory competitive tendering for refuse collection contracts. Rev ind organ, 18(1), 105-113.

Jacobsen, R., Buysse, J. and Gellynck, X. (2013). Cost comparison between private and public collection of residual household waste: multiple case studies in the Flemish region of Belgium. Waste manage, 33(1), 3-11.

Kinnaman, T. C., and Fullterton, D. (1999). The economics of residential solid waste management. NBER Working Paper No. 7326. National bureau of economic research.

Massarutto, A. (2007). Municipal waste management as a local utility: Options for competition in an environmentally-regulated industry. Util policy, 15(1), 9-19.

Ochrana, F., Fantová Šumpíková, M., Pavel, J., Nemec, J. et al. (2007). Efektivnost zabezpečování vybraných veřejných služeb na úrovni obcí. Praha: Nakladatelství Oeconomica, 152 p., ISBN 978-80-2451259-4.

Simões, P., Cruz, N. F. and Marques, R. C. (2012). The performance of private partners in the waste sector. J clean prod, 29, 214-221.

Szymanski S. (1996). The impact of compulsory competitive tendering on refuse collection services. Fiscal stud, 17(3), 1-19.

Szymanski, S. and Wilkins, S. (1993). Cheap rubbish? Competitive tendering and contracting out in refuse collection-1981-88. Fisc stud, 14(3), 109-130. 